\title{
Characterization of CYP2A13*2, a variant cytochrome P450 allele previously found to be associated with decreased incidences of \\ lung adenocarcinoma in smokers
}

\author{
Jaime D’Agostino, Xiuling Zhang, Hong Wu, Guoyu Ling, Suping Wang, Qing-Yu Zhang, \\ Fucai Liu, and Xinxin Ding \\ Wadsworth Center, New York State Department of Health, and School of Public Health, SUNY at \\ Albany, Albany, NY (J.D., X.Z., H.W., G.L., S.W., Q.-Y.Z., X.D.), Department of Epidemiology, \\ Shanxi Medical University, Taiyuan, China (S.W.), and Department of Thoracic Surgery, Shanxi \\ Tumour Hospital (F.L.), Taiyuan, China
}

\begin{abstract}
CYP2A13, a human cytochrome P450 enzyme expressed mainly in the respiratory tract, is believed to play an important role in the initiation of smoking-induced lung cancer. CYP2A13.1 has a high efficiency in the metabolic activation of a major tobacco-specific carcinogenic nitrosamine, 4(methylnitrosamino)-1-(3-pyridyl)-1-butanone (NNK). CYP2A13*2, a variant allele, was previously found to be associated with decreased incidences of lung adenocarcinoma in smokers. The aim of the present study was to determine whether the CYP2A13.2 protein has decreased enzyme activity and/or expression levels in the lung, compared to CYP2A13.1. CYP2A13.2 has two sequence variations from CYP2A13.1: Arg25Gln and Arg257Cys. We compared the activities of heterologously expressed CYP2A13.1 and CYP2A13.2 toward several known CYP2A13.1 substrates: NNK, $N$-nitrosomethylphenylamine, $N, N$-dimethylaniline, $2^{\prime}$-methoxyacetophenone, and hexamethylphosphoramide. Our results indicated that CYP2A13.2 was $20-40 \%$ less active than CYP2A13.1, with the substrates tested. We also determined the levels of the CYP2A13*2 mRNA, relative to the level of the CYP2A13*1 mRNA, in the lung tissue from *1/*2 heterozygotes. We found that the CYP2A13*2 allele was associated with a level of allelic expression $\sim 40 \%$ lower than that of the CYP2A13*1 allele. Sequence analysis of the promoter region of the CYP2A13*2 allele identified a 26-nucleotide deletion. Functional analysis of a 2-kilobasepair CYP2A13-luciferase promoter construct indicated that the 26-nucleotide deletion causes decreases in CYP2A13 promoter activity in the A549 human lung cell line. These findings suggest that the reported association of the CYP2A13*2 allele with decreased incidences of lung adenocarcinoma in smokers can be at least partly explained by a decrease in CYP2A13 function.
\end{abstract}

CYP2A13, a cytochrome P450 (P450) monooxygenase, is encoded by a functional member of the human CYP2A gene subfamily (Fernandez-Salguero et al., 1995; Su et al., 2000). The CYP2A13 gene is selectively expressed in the respiratory tract (Su et al., 2000), and the CYP2A13 protein has been detected in adult human lung (Zhu et al., 2006; Zhang et al., 2007). Heterologously expressed CYP2A13 has a catalytic efficiency greater than that of any other human P450 enzymes examined to date, for the metabolic activation of a major tobaccospecific procarcinogen, 4-(methylnitrosamino)-1-(3-pyridyl)-1-butanone (NNK) (Jalas et al., 2005). CYP2A13 also catalyzes the metabolic activation of other chemical carcinogens, such

ADDRESS CORRESPONDENCE TO: Dr. Xinxin Ding, Wadsworth Center, New York State Department of Health, Empire State Plaza, Box 509, Albany, NY 12201-0509,.Tel. 518-486-2585; Fax: 518-473-8722; E-mail: xding @wadsworth.org.

Address reprint requests to: Dr. Xinxin Ding, Wadsworth Center, New York State Department of Health, Empire State Plaza, Box 509, Albany, NewYork, 12201-0509 
as 4-(methylnitrosamino)-1-(3-pyridyl)-1-butanol (NNAL) (Jalas et al., 2003), 4aminobiphenyl (Nakajima et al., 2006), and aflatoxin $\mathrm{B}_{1}$ (He et al., 2006). The combination of the high catalytic efficiency toward NNK, the tissue-selective expression of CYP2A13 mRNA and CYP2A13 protein in human respiratory tract, and the finding that levels of CYP2A13 protein expression correlate with rates of lung microsomal NNK metabolic activation (Zhang et al., 2007), strongly suggests that CYP2A13 plays an important role in the metabolic activation of NNK in the respiratory tract of human smokers.

Many single-nucleotide polymorphisms (SNPs) have been identified in $C Y P 2 A 13$. The potential impact of SNPs on CYP2A13 expression has been demonstrated for alleles containing a $7520 \mathrm{C}>\mathrm{G}$ variation, which is associated with lowered allelic expression (Zhang et al., 2004). The functional consequences of several missense SNPs, including an Arg257Cys variation in exon 5, have been investigated (Zhang et al., 2002; Schlicht et al., 2007; Wang et al., 2006). The Arg257Cys variation, which resulted in modest decreases in metabolic activities toward NNK and other CYP2A13 substrates (Zhang et al., 2002; Schlicht et al., 2007), was found to be significantly associated with substantially reduced risks for smoking-related lung adenocarcinoma in a Chinese population, especially among light smokers (Wang et al., 2003). However, given the relatively small decrease in metabolic activity reported for the Arg257Cys variant, it has been questioned whether the Arg257Cys variation is directly responsible for the protective effects that were seen in the epidemiological study (Zhang et al., 2002; Wang et al., 2006).

The Arg257Cys variation is one of the structural features in the protein encoded by the CYP2A13*2 allele, which contains an additional missense variation in exon 1 (Arg25Gln) (Zhang et al., 2003, Jiang et al., 2004). However, it remained to be determined whether the Arg25Gln and Arg257Cys double variant (CYP2A13.2) shows decreased metabolic activity toward NNK, as compared with the activity of the wild-type (WT) protein (CYP2A13.1). Furthermore, it was not known whether the CYP2A13*2 allele is associated with altered CYP2A13 gene expression. A combination of changes in metabolic activity and changes in gene expression might better explain the significant protective effects seen in the epidemiological study referenced above. Thus, the aim of the present study was to answer these remaining questions, in order to obtain mechanistic support for a causal relationship between the CYP2A13*2 allele and the reduced risks for lung adenocarcinoma. The CYP2A13.2 protein was generated by site-directed mutagenesis and heterologous expression in insect Sf9 cells. Using CYP2A13.2, we tested the combined effects of the Arg257Cys and Arg25Gln substitutions on CYP2A13 enzyme activity. In addition, using adult human lung tissues, we quantified the expression of the CYP2A $13 * 2$ allele, as compared to the expression of the CYP2A13*1 allele, in heterozygous individuals, and we also compared total CYP2A13 mRNA levels between $* 1 / * 1$ and heterozygous $* 1 / * 2$ individuals. Finally, we sequenced the upstream region of the $C Y P 2 A 13$ gene promoter, in order to identify additional polymorphisms that might cause altered expression of the CYP2A $13 * 2$ allele. Our findings indicate that the CYP2A13*2 allele is associated with decreased metabolic activity as well as decreased CYP2A13 mRNA expression, and they suggest that the reported protective effects of the CYP2A $13 * 2$ allele in light smokers are at least partly due to a decrease in CYP2A13 function.

\section{Materials and Methods}

\section{Site-Directed Mutagenesis and Heterologous Expression of the CYP2A13 Arg25GIn/ Arg257Cys Variant in Insect Sf9 Cells}

The $74 \mathrm{G}>\mathrm{A}$ point mutation found in exon 1 of the $C Y P 2 A 13$ gene was introduced into the 3375C> T CYP2A13 cDNA (Zhang et. al., 2002) or the WT CYP2A13 cDNA (Su et al., 2000), both in the pCR-Script vector (Stratagene, La Jolla, CA); the QuikChange site-directed mutagenesis kit (Stratagene) was used, yielding expression vectors for the production of the 
CYP2A13.2 protein and the CYP2A13 Arg25Gln variant. Two complementary mutagenic oligonucleotide primers were used to introduce the exon-1 variation: $5^{\prime}$ gtcttgatgtcagtctggcAgcagaggaagagcagg-3' (sense) and 5'cctgctcttcctctgcTgccagactgacatcaagac-3' (antisense), with the upper-case letter indicating the changed nucleotide. Mutagenesis reactions were performed essentially according to the manufacturer's instructions. The resulting plasmids were analyzed by sequencing, in order to confirm the nucleotide changes and the integrity of the variant cDNA. Heterologous expression of the Arg25Gln, Arg257Cys, Arg25Gln/Arg257Cys (CYP2A13.2), and the WT Arg25/ Arg257 (CYP2A13.1) proteins in Sf9 cells was performed as previously described (Su et al., 2000; Zhang et al., 2002). Microsomal fractions, prepared as described earlier (Liu et al., 1996), were stored at $-80^{\circ} \mathrm{C}$ until use. $\mathrm{P} 450$ protein expression was confirmed by immunoblot analysis of microsomal proteins with a rabbit anti-mouse CYP2A5 antibody (Gu et al., 1998).

\section{Determination of Catalytic Activity}

Formaldehyde, formed from hexamethylphosphoramide (HMPA), 2'-methoxyacetophenone (2'-MAP), $N, N$-dimethylaniline (DMA), and $N$-nitrosomethylphenylamine (NMPhA), was measured in incubations with CYP2A13.1 and CYP2A13.2 in Sf9 microsomes, as described previously (Su et al., 2000), according to the method of Nash (1953). The rates of product formation were corrected for zero time blanks that were quenched before the addition of NADPH. Reactions were carried out at $37^{\circ} \mathrm{C}$ for $20 \mathrm{~min}$. The enzyme activities were linear with incubation time under the conditions used.

NNK metabolism was performed essentially as previously described (Su et al., 2000). [5- $\left.{ }^{3} \mathrm{H}\right]$ NNK $(10.9 \mathrm{Ci} / \mathrm{mmol}$; purity $>98 \%)$ was purchased from Moravek Biochemicals, Inc. (Brea, CA) and unlabeled NNK was purchased from Chemsyn Science Laboratories (Lenexa, KS). All other chemicals were obtained from Sigma-Aldrich (St. Louis, MI). The radiolabeled NNK was further purified by reverse-phase HPLC before use. For inhibition studies, inhibitors were added at $0-50 \mu \mathrm{M}$ in $2 \mu \mathrm{l}$ methanol. Reactions were carried out at $37^{\circ} \mathrm{C}$ for 5 to $10 \mathrm{~min}$, and terminated with $50 \mu \mathrm{l}$ each of $25 \%$ zinc sulfate and saturated barium hydroxide. The samples were spun, and $75 \mu \mathrm{l}$ aliquots were injected, for analysis in a reverse-phase HPLC system consisting of a Model 600S controller, a Model 626 pump, a Model 717 Plus autosampler (Waters, Milford, MA), equipped with a Radiomatic Series A-500 Radio-Chromatography Detector (Perkin Elmer, Waltham, MA). The HPLC conditions used were the same as previously described, with the analyses performed in the presence of sodium bisulfite ( $\mathrm{Su}$ et al., 2000), except that $20 \mathrm{mM}$ Tris-HCl buffer, $\mathrm{pH}$ 5.0, was used, a condition that was found to increase the stability of the keto aldehyde during analysis. Non-linear regression and enzyme kinetic analyses were performed with the GraphPad Prism 5 software (GraphPad Software, San Diego, CA).

\section{Immunoblot Analysis}

Electrophoresis was carried out with NuPage 10\% Bis-Tris 1-mm-thick gels (Invitrogen, Carlsbad, CA) using an XCell SureLock ${ }^{\mathrm{TM}}$ Mini-Cell system (Invitrogen). After electrophoresis, proteins were transferred to nitrocellulose membranes, and then incubated with a polyclonal anti-CYP2A5 (Gu et al., 1998), a monoclonal anti-CYP2A6 from Invitrogen (\#151-45-4), or a monoclonal anti-CYP2A6 from Gentest (\#A106; Woburn, MA), for immunoblot analysis. The nitrocellulose membrane was first blocked in TBST buffer (Trisbuffered saline containing $0.1 \%$ Tween-20) and $5 \%$ milk, overnight at $4^{\circ} \mathrm{C}$. The nitrocellulose membrane was then incubated with a 1:2000 dilution of anti-CYP2A5 in TBST containing 5\% milk, or a 1:1000 dilution of the anti-CYP2A6 in TBST containing $0.5 \%$ milk. The nitrocellulose membrane was then washed in TBST, and incubated, at room temperature, with a 1:10,000 dilution of peroxidase-conjugated goat anti-rabbit immunoglobin $\mathrm{G}$ (for anti- 
CYP2A5) or goat anti-mouse immunoglobin G (for anti-CYP2A6). Immunoblot analysis was performed with an enhanced chemiluminescence kit from Amersham (Pittsburgh, PA). Heterologously expressed CYP2A6 in Sf9 cell microsomes (Liu et al., 1996) was used as a positive control, and microsomes from un-infected Sf9 cells were used as a negative control. For quantitative analysis, a digitized image of an immunoblot was analyzed with the Labworks software (UVP, Upland, CA).

\section{Preparation of DNA, RNA, and First-strand cDNA}

DNA and RNA were isolated from resected normal lung biopsy tissues (provided by the National Cancer Institute Cooperative Human Tissue Network or the Shanxi Tumour Hospital, Taiyuan, China), and from human fetal autopsy tissues (non-cancerous; provided by the University of Washington Birth Defects Research Laboratory, Seattle, WA). DNA from tissue samples, used for the identification of individuals heterozygous for the 3375C $>\mathrm{T}$ variation, were isolated using a DNeasy tissue kit (QIAGEN, Valencia, CA). Total RNA was isolated from normal lung tissues with use of an RNeasy Mini kit (QIAGEN). Total RNA was pretreated with DNase I (Invitrogen) to exclude genomic DNA contamination. First-strand cDNA was synthesized from $2 \mu \mathrm{g}$ of total RNA in a total volume of $20 \mu \mathrm{l}$, using the SuperScript III firststrand synthesis system and an Oligo(dT) 20 primer (Invitrogen). This study was approved by the Institutional Review Boards of the participating institutions.

\section{Quantitative Analysis of CYP2A13 Expression}

Allelic expression analysis for CYP2A13*1 and CYP2A13*2 mRNAs was conducted according to the general method previously described for the allelic expression analysis of the CYP2A13 7520C/G alleles (Zhang et al., 2004). First-strand cDNA was synthesized as described above. A 531-bp fragment (exons 3 to 6 ) of the CYP2A13 cDNA was amplified by PCR using the primers 2A13E3F-RT2 (5'-aggcgcggcatcgaggaa-3') and 2A13E6R-RT2 (5'cgcaaagaagaggttcagg-3'). PCR was carried out using a LightCycler and the LightCycler FastStart DNA Master SYBR Green I kit (Roche Applied Sciences, Indianapolis, IN). Reaction mixtures, in a total volume of $20 \mu \mathrm{l}$, contained $4 \mu \mathrm{l}$ of 1 st-strand cDNA, $3.0 \mathrm{mM} \mathrm{MgCl} 2,0.4$ $\mu \mathrm{M}$ each primer, and $2 \mu \mathrm{l}$ of the Master mix. After a preincubation at $95^{\circ} \mathrm{C}$ for $8 \mathrm{~min}$, the reaction was carried out for 60 cycles, with each cycle consisting of a denaturation at $95^{\circ} \mathrm{C}$ for $15 \mathrm{~s}$, an annealing at $66^{\circ} \mathrm{C}$ for $10 \mathrm{~s}$, and an extension at $72^{\circ} \mathrm{C}$ for $25 \mathrm{~s}$, followed by a final extension at $72^{\circ} \mathrm{C}$ for $1 \mathrm{~min}$. A nested PCR was carried out using the primers 2A13E4F2 (5'gcgccaatatcgatcccacct-3') and 2A13E6-RT1 (5'-cgcaaagaagaggttcagg-3'), and hybridization probes designed and synthesized by TIB MolBiol (Adelphia, NJ). The sequences of Anchor and Sensor probes (with the variation sites in upper case) are as follows: Anchor probe, 5'ccaccttcttggcgatgaagtcctcc-fluorescein-3'; Sensor [C] probe, 5'-LightCycler Red-640gcgtgcGctggttgtgc-phosphate-3' (for the CYP2A13*1 allele); and Sensor [T] probe, 5'-LCRed640-cagcgtgcActggttgtgc-phosphate-3' (for the CYP2A13*2 allele). The reaction mixtures, in a total volume of $10 \mu \mathrm{l}$, contained $2 \mu \mathrm{l}$ of the 531-bp fragment (gel-purified) from the first PCR, $3.0 \mathrm{mM} \mathrm{MgCl}_{2}, 0.4 \mu \mathrm{M}$ each primer, $0.3 \mu \mathrm{M}$ Sensor [C] or Sensor [T] probe, $0.3 \mu \mathrm{M}$ Anchor probe, and $1 \mu \mathrm{l}$ LightCycler FastStart hybridization probe reagent mix. After pre-denaturation at $95^{\circ} \mathrm{C}$ for $8 \mathrm{~min}$, reactions were carried out for 50 cycles (with each cycle consisting of a denaturation at $95^{\circ} \mathrm{C}$ for $10 \mathrm{~s}$, an annealing at $65^{\circ} \mathrm{C}$ for $10 \mathrm{~s}$, and an extension at $72^{\circ} \mathrm{C}$ for $18 \mathrm{~s}$ ), followed by a final extension at $72^{\circ} \mathrm{C}$ for $1 \mathrm{~min}$. Fluorescence was monitored at $65^{\circ} \mathrm{C}$. Standard curves were generated in reactions with known ratios of the $* 1$ and $* 2$ templates $(1: 5,1: 3,1: 1,3: 1,5: 1$, as well as $* 1$ only and $* 2$ only), which were purified PCR products amplified from cloned $C Y P 2 A 13$ gene fragments. Each quantitative PCR run also included a no-template control. Melting-curve analysis, calculation of peak-height ratios, and transformation into template ratio were all conducted as described previously (Zhang et al., 2004). 


\section{Measurement of total CYP2A13 mRNA}

The total CYP2A13 mRNA levels, as well as the mRNA level for the housekeeping gene $\beta$ actin, were determined by real-time PCR using an ABI 7500 Fast Real-Time PCR System and SYBR Green PCR Core Reagents (Applied Biosystems, Foster City, CA). Total RNA extraction and first-strand synthesis were carried out as described above. The primers used were $2 \mathrm{~A} 13-\mathrm{F}$ and $2 \mathrm{~A} 13-\mathrm{R}$ for CYP2A13, and $\beta$-actin-F and $\beta$-actin-R for $\beta$-actin (Zhang et al., 2004). The expected sizes of PCR products were 204 base pairs (bp) for CYP2A13 and 396 bp for $\beta$-actin. Reaction mixtures for CYP2A13 contained $2 \mu 1$ reverse transcription product, $3 \mathrm{mM} \mathrm{MgCl} 2,0.3 \mu \mathrm{M}$ each primer, $2 \mu \mathrm{l}$ of $10 \mathrm{x}$ SYBR Green PCR buffer, $1.6 \mu \mathrm{l}$ of dNTP blend, 0.2 Units AmpErase UNG, and 0.5 Units AmpliTaq Gold in a final volume of $20 \mu 1$. The reaction mixtures for $\beta$-actin were the same, except that $0.4 \mu \mathrm{M}$ each primer was used; also AmpErase UNG was omitted from the reaction. Reactions were initiated with denaturation at $50^{\circ} \mathrm{C}$ for $2 \mathrm{~min}$ (this step was omitted for $\beta$-actin), and then $95^{\circ} \mathrm{C}$ for $8 \mathrm{~min}$, followed by 40 to 50 cycles of amplification $\left(\mathrm{CYP} 2 \mathrm{~A} 13\right.$ : 50 cycles of $95^{\circ} \mathrm{C}$, for $10 \mathrm{~s}$, and $64^{\circ} \mathrm{C}$, for $1 \mathrm{~min} ; \beta$ actin: 40 cycles of $95^{\circ} \mathrm{C}$ for $10 \mathrm{~s}, 62^{\circ} \mathrm{C}$ for $10 \mathrm{~s}$, and $72^{\circ} \mathrm{C}$ for $30 \mathrm{~s}$ ). Fluorescence was monitored at $64^{\circ} \mathrm{C}$ for CYP2A 13 and at $72^{\circ} \mathrm{C}$ for $\beta$-actin. All quantitative PCR reactions were performed in duplicate and included standards (10-fold serial dilutions of cloned cDNA for CYP2A13, and 10 -fold serial dilutions of gel-purified reverse transcription-PCR products for $\beta$-actin), a no-template control, and the first-strand cDNA samples. The data were evaluated with the ABI 7500 Fast System SDS software (Applied Biosystems). The relative levels of CYP2A13 mRNA were normalized as number of copies of CYP2A13 cDNA per 100,000 copies of $\beta$ actin cDNA.

\section{DNA Sequence and Genotype Analysis}

For identification of promoter-region SNPs or other types of sequence variations, a 2304-bp fragment, between -2059 and $244 \mathrm{bp}$, of the CYP2A13 gene was amplified using primers 2A13up-2059F and 2A13int1R (Fujieda et al, 2003). PCR was carried out on a GeneAmp PCR System 9600 (Perkin Elmer). PCR products were gel-purified using a QIAquick Gel Extraction kit (QIAGEN) and then subjected to direct sequencing using the primers 2A13up-2059F, 2A13up-Seq4 (5'-agtgtgtccactgctgatgc-3'), 2A13_5UR (5'-ggtgtagttgggaggtgaaatg-3'), and 2A13up-Seq1 (5'-gcttgctacacactccacct-3').

For detection of SNPs representing CYP2A13*3,*4, $* 5, * 6, * 7, * 8$, and $* 9$ alleles, exons $2,3,6$, 9 , and the 3 '-untranslated region (UTR) of all adult human lung samples used in the study were amplified using primers exon $2 \mathrm{~F}$ and exon $2 \mathrm{R}$, exon $3 \mathrm{~F}$ and exon $3 \mathrm{R}$, and exon $6 \mathrm{~F}$ (all described by Zhang et al., 2002); exon 6R2 (5'-actggaaagggaggaaagtga-3'); and exon 8F and 2A13R2 (Zhang et al., 2004). A no-template control was routinely used for detecting potential contamination of reagents. PCR products were gel-purified, and then subjected to direct sequencing using the primers exon $2 \mathrm{~F}$, exon $3 \mathrm{~F}$, exon $6 \mathrm{~F}$, and exon $9 \mathrm{R}\left(5^{\prime}-\right.$ gatgtccttcagagctgtga- $3^{\prime}$ ). DNA sequencing was performed using an automated DNA sequencer from Applied Biosystems (model 3100) at the Molecular Genetics Core of the Wadsworth Center.

\section{Reporter Plasmid Construction, Cell Culture, Transfection, and Luciferase Reporter Assays}

The 2304-bp CYP2A13 promoter fragment was amplified from individuals identified as either WT or heterozygous for the 26-bp deletion using the primer pair 2A13up-2059F and 2A13int1R. Following a 10-fold dilution of the PCR products, a 394-bp fragment ( -2059 to -1666) was amplified using the following primers: 5'-ggcggcgagctcacatcagagcctgtcctgtgc-3' (forward), containing a SacI site (underlined), and 5'-catcagcagtggacacactg-3' (reverse). The resulting PCR fragments, which also contained an EcoRV site (at -1707), were digested with SacI and EcoRV; the resultant 353-bp SacI-EcoRV fragment was used to replace the 468-bp SacI-EcoRV fragment at the 5'-end of the p2A13_2153 vector (Ling et al., 2007), yielding the 
p2A13*1 (containing -2059 to +17 of the $C Y P 2 A 13$ gene sequence) and $\mathrm{p} 2 \mathrm{~A} 13 * 1 \Delta 26$ luciferase reporter constructs. CYP2A13 sequences in these promoter constructs were confirmed to be identical to a reference sequence (GenBank accession number NG_000008), except for the 26-bp deletion.

Human lung cancer A549 cells (ATCC \#CCL-185, Manassas, VA), cultured in Ham's F-12k medium (Sigma-Aldrich) supplemented with $10 \%$ fetal bovine serum, were transfected with a CYP2A13 reporter construct, or pGL3_Basic (vector control), both encoding a firefly luciferase, as well as the pRL-SV40 Renilla luciferase construct (Promega, Madison, WI) as an internal standard. Cells were cultured in 6-well plates, maintained in a humidified 5\% $\mathrm{CO}_{2}$ atmosphere at $37^{\circ} \mathrm{C}$. Transfections were done in duplicate, with two different DNA preparations (each consisting of $0.3 \mathrm{pmol}$ of a reporter gene construct and 3 fmol of pRLSV40), and using Lipofectamine 2000 (Invitrogen). Cells were harvested $48 \mathrm{~h}$ after transfection. The Dual Luciferase Reporter Assay System (Promega) was used for determination of the relative luciferase activities. Luminescence was measured using a Berthold model LB9501 luminometer (Bad Wildbad, Germany). For each sample, the activity of the firefly luciferase was normalized by that of the Renilla luciferase, in order to correct for differences among wells in cell density and transfection efficiency.

\section{Other Materials and Methods}

CO-difference spectra of microsomal P450 were recorded at room temperature using a Cary 3E spectrophotometer (Varian, Mulgrave, Australia), according to the procedure described by Omura and Sato (1964). Protein concentrations were determined by the bicinchoninic acid method (Pierce, Rockford, IL), with bovine serum albumin used as the standard. Rat CPR was obtained as described elsewhere (Zhang et al., 1998). Gel-purification was performed using a QIAquick Gel Extraction Kit (QIAGEN). PCR-restriction fragment length polymorphism analysis, as described previously (Zhang et al., 2002), was used to identify tissue samples heterozygous for the $3375 \mathrm{C}>\mathrm{T}$ variation. Student's $t$ test was used to examine the significance of either differences in metabolic activities between CYP2A13.1 and CYP2A13.2, or else differences in activities between the p2A13*1 and p2A13*1 $\Delta 26$ luciferase reporter constructs. The Sign Test (Rosner 2006) was used to determine the significance of differences between the relative allelic expression of the CYP2A13*1 allele and that of the CYP2A13*2 allele.

\section{Results}

\section{Heterologous Expression and Functional Characterization of the CYP2A13.2 Variant}

A cDNA for the CYP2A13.2 variant was generated and cloned into a baculoviral vector for expression in insect Sf9 cells. The sequence of the CYP2A13.2 cDNA insert in the baculoviral expression vector, and the sequences at the cloning sites, were confirmed. The yield of P450 in lysate from recombinant virus-infected Sf9 cells ranged from 10 to $39 \mathrm{nmol} / \mathrm{L}$ in different batches of cells cultured with the addition of hemin. The level of the cytochrome in the microsomal fractions ranged from 0.17 to $0.83 \mathrm{nmol} / \mathrm{mg}$ of protein.

A typical P450 CO-difference spectrum with an absorbance maximum at $452 \mathrm{~nm}$ was recorded with detergent-solubilized microsomal preparations from CYP2A13.2-expressing Sf9 cells (data not shown). The CYP2A13.2 protein expression was confirmed by immunoblot analysis, in which a single band of the expected size was detected for the microsomal fraction of CYP2A13.2-expressing cells, but not for the microsomal fraction of control Sf9 cells (data not shown).

The activities of the CYP2A13.1 and CYP2A13.2 proteins toward four known CYP2A13 substrates, HMPA, DMA, 2'-MAP, and NMPhA, were examined. The CYP2A13.2 protein 
was less active toward all four compounds than was the CYP2A13.1 protein, with the extents of decrease in activity ranging from $19 \%$ to $34 \%$ (Table 1). The decreases in turnover number were statistically significant for all four compounds tested.

The metabolic activity of CYP2A13.2 toward NNK was also compared to that of the CYP2A13.1 protein. The CYP2A13.2 protein had significantly lower $\mathrm{V}_{\max }$ values for both keto aldehyde and keto alcohol formation (Table 2). The extent of decrease in $\mathrm{V}_{\max }$ of the CYP2A13.2 protein, compared to the CYP2A13.1 protein, was $~ 29 \%$ and $\sim 4 \% \%$ for the keto aldehyde and keto alcohol, respectively. The apparent $K_{\mathrm{m}}$ values were not statistically different for either product when compared to the CYP2A13.1 $K_{\mathrm{m}}$ values, and they were similar between keto aldehyde and keto alcohol formation. No other products were detected by radiometric high-pressure liquid chromatography.

The CYP2A13.1 and CYP2A13.2 proteins are expected to co-exist in $* 1 / * 2$ heterozygous individuals. To test the hypothesis that the CYP2A13.2 protein can inhibit the activity of the CYP2A13.1 protein, possibly through competition for available CPR in the microsomal membrane, the activities of a 1:1 mix of the two proteins toward NNK were compared to the activities of each enzyme alone, with various levels of CPR used in the reconstituted system. As expected, lowering the amount of CPR decreased the rate of keto aldehyde formation. Nonetheless, the rate for the CYP2A13.1 and CYP2A13.2 mix was not different from the averaged rates for each individual enzyme, at all CYP to CPR ratios tested (Table 3). The extent of decrease in the rate of aldehyde formation, for the CYP2A13.2 protein as compared to the CYP2A13.1 protein, was $28-35 \%$, at the various CPR levels; this extent was similar to what was observed for the magnitude of the differences seen in $\mathrm{V}_{\max }$, when the kinetic parameters were determined (Table 2). Decreases in the rate of keto alcohol production, by extents similar to those seen for keto aldehyde formation, were also observed (data not shown), although the peak areas for the keto alcohol were too small to allow accurate rate determination when lowered levels of CPR were used.

\section{Effects of CYP2A Inhibitors on CYP2A13.1 and CYP2A13.2}

We tested CYP2A inhibitors, to determine whether they differentially inhibited the CYP2A13.1 and CYP2A13.2 proteins; allele-specific inhibitors would be useful for determination of the relative contribution of each protein to total microsomal metabolism. Miconazole, a potent CYP2A5 and CYP2A6 inhibitor (Draper et al., 1997, Mäenpää et al., 1993); metyrapone, a potent inhibitor of CYP2A5 but not CYP2A6 (Mäenpää et al., 1993); tranylcypromine, a potent CYP2A6 and CYP2A13 inhibitor (Draper et al., 1997; Nakajima et al., 2006); and 8-methoxypsoralen, a potent CYP2A5, CYP2A6, and CYP2A13 inhibitor (von Weymarn et al., 2005, Draper et al., 1997, Mäenpää et al., 1993), were all tested with both CYP2A13.1 and CYP2A13.2, with NNK as the substrate. All four CYP2A inhibitors showed strong inhibition of keto aldehyde formation for both CYP2A13.1 and CYP2A13.2 (Fig. 1). Keto alcohol formation was also potently inhibited for both enzymes; total inhibition was achieved at lower concentrations of inhibitor for keto alcohol formation than for keto aldehyde formation (data not shown). For each compound, the extent of inhibition (\% of control) was similar between the two CYP2A13 proteins, indicating that the two forms cannot be distinguished by any of the CYP2A inhibitors tested. To our knowledge, this is the first report of miconazole or metyrapone as an inhibitor of CYP2A13.

\section{Immunoblot Analysis of CYP2A13.1 and CYP2A13.2 Proteins}

The CYP2A13.1 and CYP2A13.2 proteins could not be resolved on immunoblots, even with the recently described high-resolution gel electrophoresis system, a system that allowed resolution of CYP2A13.1 and CYP2A6 (Wong et al., 2005) (data not shown). An anti-2A13 peptide antibody has been described (Zhu et al., 2006); however, the epitope detected by that 
antibody is far from the two variant residues in the CYP2A13.2 protein. Therefore, it is unlikely that the anti-2A13 peptide antibody will distinguish CYP2A13.1 from CYP2A13.2. The epitopes recognized by several other available anti-CYP2A antibodies, which might also crossreact with CYP2A13, have not been identified; those antibodies may recognize epitopes that are affected by the amino-acid changes in the CYP2A13.2 protein. Thus, we chose two monoclonal anti-CYP2A6 antibodies (\#A106 from Gentest, and \#151-45-4 from Invitrogen) and, as a control, a polyclonal anti-CYP2A5 antibody, in a further attempt to distinguish between the CYP2A13.1 and CYP2A13.2 proteins on immunoblots. CYP2A6 was detected by all three antibodies tested, while CYP2A13.1 and CYP2A13.2 were detected only by the anti-CYP2A5 and the A106 anti-CYP2A6, but not by the 151-45-4 anti-CYP2A6 (Fig. 2); the 151-45-4 anti-CYP2A6 could, however, weakly react with CYP2A13.1 under less stringent conditions (data not shown). The A106 anti-CYP2A6 antibody had an apparently lower binding affinity for CYP2A13.2 than for CYP2A13.1 (panel C); the magnitude of the difference in binding affinity was estimated to be $\sim 50 \%$ by densitometric analysis. This differential binding was in contrast to the apparently equal binding affinity of the polyclonal anti-CYP2A5 antibody for the two CYP2A13 proteins (panel A). Further analysis using Arg25Gln and Arg257Cys single variant proteins demonstrated that A106 had a similar decrease in binding affinity for the Arg257Cys variant, but not the Arg25Gln variant (Fig. 2, panel D), a result indicating that the epitope recognized by A106 is somewhat altered by the Arg257Cys change. In control experiments (panel E), the anti-CYP2A5 polyclonal antibody had comparable affinity for the Arg257Cys and the Arg25Gln variants.

\section{Sequence Analysis for Adult Human Lung Samples}

The DNA from human lung samples used for relative allelic expression analysis and measurement of total CYP2A13 mRNA was sequenced for known SNPs in CYP2A13 exons 2, 3, 6, 9, and the 3'-UTR, in order to confirm that the samples used were of either CYP2A13*1/ $* 1$ or CYP2A $13 * 1 / * 2$ genotype, and that they did not contain the $7520 \mathrm{C}>\mathrm{G}$ variation known to be associated with decreased allelic expression. Sequence analysis revealed that none of the tissue samples contained any of the following alleles (represented by the SNPs shown in the parentheses): *3 (1706C>G), *4 (579G >A ), *5 (7343T>A), *6 (7465C>T), *7 (578C > T), *8 $(1706 \mathrm{C}>\mathrm{G})$, or $* 9(5294 \mathrm{G}>\mathrm{T})$; neither did they contain the $7520 \mathrm{C}>\mathrm{G}$ change. Therefore, the samples identified as heterozygous for the $3375 \mathrm{C}>\mathrm{T}$ variation by restriction fragment length polymorphism are all from $* 1 / * 2$ individuals, and the samples negative for the $3375 \mathrm{C}>\mathrm{T}$ variation are all from $* 1 / * 1$ individuals.

\section{Relative Expression Level of the CYP2A13² Allele in Human Lung}

Tissues from eight individuals (4 Caucasians and 3 African-Americans, and 1 of unknown race; 3 male, 5 female; $38-79$ years of age at the time of lung tissue biopsy), identified by restriction fragment length polymorphism and genotyping analyses as $* 1 / * 2$ heterozygotes, were used to determine whether the CYP2A13*2 allele has a lower expression level in the lung, compared to the CYP2A13*1 allele, by allele-specific quantitative RNA-PCR. The relative allelic expression levels (ratios) for the CYP2A13*1 and CYP2A13*2 mRNAs ranged from 1.1 to 2.7 (3375C:3375T) when assayed using the $3375 \mathrm{C}$ probe. Use of the $3375 \mathrm{~T}$ probe gave similar results, with C:T ratios ranging from 1.1 to 2.7. The averaged C:T ratios for the eight individuals were $1.5 \pm 0.5$ and $1.7 \pm 0.6$, for the $3375 \mathrm{~T}$ and $3375 \mathrm{C}$ probes, respectively (means \pm S.D.; $\mathrm{p}<0.05$, Sign Test). The results indicate that the CYP2A $13 * 2$ mRNA is, on average, expressed at levels 30-40\% lower than the levels of the CYP2A13*1 mRNA.

The epidemiological study that identified an association between the CYP2A13*2 allele and decreased lung cancer incidence in smokers was performed in a Chinese population (Wang et al., 2003). We considered the possibility that the expression differences between CYP2A13*1 and CYP2A13*2 alleles differ between Chinese and other ethnic groups. Therefore, we further 
examined the relative allelic expression of the CYP2A13*1 and CYP2A13*2 alleles in tissues from five Chinese heterozygotes. We found that the averaged C:T ratios were similar in the five Chinese lung samples (1.6 \pm 0.6 ; means \pm S.D.) and the seven Caucasian/African American samples $(1.7 \pm 0.6)$; since there were no significant differences between results obtained with the $3375 \mathrm{C}$ and $3375 \mathrm{~T}$ probes, we averaged the results for the two probes for each sample in these comparisons. We also confirmed that there was no sequence variation at the primer or probe binding sites in any of the samples tested (data not shown).

\section{Comparison of Total CYP2A13 mRNA Levels in Lung Tissues from ${ }^{*} \mathbf{1} /{ }^{*} \mathbf{1}$ and ${ }^{*} \mathbf{1} /{ }^{\star} \mathbf{2}$ Individuals}

Total CYP2A13 mRNA levels were determined using real-time PCR with CYP2A13 genespecific primers in 21 human lung samples ( 1 of unknown race, 12 Caucasians, and 8 AfricanAmericans; 6 male, 15 female; $42-86$ years of age at the time of lung tissue biopsy). The 21 tissue samples were derived from $11 * 1 / * 1$ individuals and $10 * 1 / * 2$ individuals. The CYP2A13 mRNA levels were normalized by the level of $\beta$-actin mRNA in the same lung samples. The expression level in CYP2A13*1/*1 samples $\left(30 \pm 26\right.$ copies of CYP2A13/10 ${ }^{7}$ copies of $\beta$ actin; means \pm S.D.) was higher than that in CYP2A13*1/*2 samples $(18 \pm 21$ copies of CYP2A13/10 7 copies of $\beta$-actin); however, the difference between the two groups was not statistically significant ( $p>0.05$, Mann-Whitney rank sum test). There was a large (70-fold) inter-sample variation in mRNA levels in both groups.

\section{Identification of A Novel 26-bp Deletion in the CYP2A13 5'-flanking Region}

Two fetal lung samples, which were identified in preliminary studies as having low expression of CYP2A13 mRNA, were found to be heterozygous for the 3375C $>\mathrm{T}$ variation that is unique to the CYP2A13*2 allele. These two samples were sequenced from -2059 to $244 \mathrm{bp}$, in an effort to identify SNPs associated with the decreased-expression phenotype. Both samples were heterozygous for four SNPs that are common to the CYP2A13*2 alleles $(-1479 \mathrm{~T}>\mathrm{C}$, $-1429 \mathrm{~A}>\mathrm{G},-1240 \mathrm{~A}>\mathrm{G}$, and $-411 \mathrm{G}>\mathrm{A}$; Human Cytochrome P450 Allele Nomenclature Committee). In addition, both samples were heterozygous for a novel 26-bp deletion (5'actcttatgccetcctgaagcaggac- $3^{\prime}$ ), identified between -1888 and $-1913 \mathrm{bp}$ of the promoter. Further sequence analysis of 11 heterozygous $* 1 / * 2$ and nine $* 1 / * 1$ adult lung biopsy samples resulted in detection of the 26-bp deletion in all $11 * 1 / * 2$ samples, but none of the $* 1 / * 1$ samples. Taken together, the data indicate that, like the $3375 \mathrm{C}>\mathrm{T}$ variation, the 26-bp deletion is unique to the CYP2A13*2 allele, although physical linkage between the 26-bp deletion and the $3375 \mathrm{C}>\mathrm{T}$ variation has yet to be confirmed experimentally.

\section{Functional Characterization of the 26-bp Deletion}

The effects of the 26-bp deletion on CYP2A13 promoter activity were tested using a reporter gene assay. A 2304-bp CYP2A13 promoter region, containing either the CYP2A13*1 sequence, or the CYP2A13*1 sequence missing the nucleotides between -1913 and -1888 , was cloned into the pGL3_Basic vector, yielding p2A13*1 and p2A13*1 $\Delta 26$ vectors, respectively (Fig. 3, panel A). The CYP2A13 promoter vectors, or the pGL3_Basic control vector, were each co-transfected with an internal standard vector into human lung cancer line A549 cells. CYP2A13 promoter activity, determined by normalization to the activity of the internal control vector, was, on average, $39 \%$ lower for the $\mathrm{p} 2 \mathrm{~A} 13 * 1 \Delta 26$ vector than for the p2A13*1 vector, based on two determinations (Fig. 3, panel B). This finding indicates that the 26-bp deletion leads to decreased promoter activity.

\section{Discussion}

We have performed a detailed comparison of the expression and function of the CYP2A $13 * 1$ and CYP2A13*2 alleles in this study. The CYP2A13.1 and CYP2A13.2 proteins differ at two amino acid positions, Arg25Gln and Arg257Cys. Compared to CYP2A13.1, the CYP2A13.2 
protein had lower activities toward several substrates, including NNK, NMPhA, 2'-MAP, DMA, and HMPA. However, the extents of activity differences between the two proteins were small ( $<2$-fold). Thus, the functional differences alone do not appear sufficient to explain the reported association of the CYP2A13*2 allele with decreased incidences of lung adenocarcinoma in smokers (Wang et al., 2003).

The present finding of small, but significant, decreases in enzyme activities toward a number of CYP2A13 substrates in CYP2A13.2, as compared to the corresponding activities of CYP2A13.1, is in contrast to the recent finding that the two CYP2A13 proteins, when heterologously expressed in Chinese hamster ovary cells, did not differ in their capacity to activate NNK and aflatoxin-B1, as determined by the capacity of these toxicants to decrease cell viability (Wang et al., 2006). Nonetheless, a small difference in enzyme activity would be difficult to detect in an assay for cell viability. In any case, the present finding is consistent with the report of Wang and coworkers (2006), in that there is no dramatic difference in enzyme activities between CYP2A13.1 and CYP2A13.2. Notably, while the kinetic parameters determined in our study for CYP2A13.1-mediated NNK metabolism are within the range of values previously reported (Bao et al., 2005; He et al., 2004; Jalas et al., 2003; Su et al., 2000), the rates found here for metabolism of HMPA, DMA, 2'-MAP, and NMPhA by CYP2A13.1 are higher than those determined previously (Zhang et al., 2002; Su et al., 2000). These rate differences are at least partly due to the use of rat CPR in this study, as opposed to the use of rabbit CPR in the previous studies on the metabolism of these four substrates (for NNK, in contrast, rat CPR was used), given the fact that rat CPR can support higher human CYP2A activities than can rabbit CPR (Ding, unpublished results).

The activity difference between CYP2A13.1 and CYP2A13.2 appears to be mainly due to the Arg257Cys change. Previous studies have shown that the Arg257Cys change alone leads to a decrease in the catalytic efficiency toward NNK, and decreases in the rates of metabolism of NMPhA, 2'-MAP, DMA, and HMPA (Zhang et al., 2002; Schlicht et al., 2007). The additional Arg25Gln change in CYP2A13.2 did not extend these functional differences. The Arg257Cys variation is located near the carboxyl end of the G-helix, according to sequence alignments (Gotoh 1992; Hasemann 1995) and the CYP2A13.1 crystal structure (Smith et al., 2007). Recent analyses of the crystal structures of several CYP2 enzymes support the idea that some conformational changes that occur with substrate binding require the various helices, including the G helix, to rotate and move (Wester et al., 2003; 2004; Scott et al., 2004); therefore, the Arg257Cys variation may well interfere with the necessary flexibility in the structure. On the other hand, it seems unlikely that the Arg257Cys variation causes a reduced interaction with CPR, given the finding from our mixing experiments with limiting amounts of CPR, namely, that CPR did not preferentially react with either CYP2A13.1 or CYP2A13.2.

In addition to the identification of activity differences between CYP2A13.1 and CYP2A13.2, we also attempted to distinguish between the two proteins through the use of chemical inhibitors, and through immunoblot analysis using two available CYP2A6 monoclonal antibodies. Interestingly, while none of the chemical inhibitors used was able to differentially inhibit the two enzymes, the A106 antibody did show a greater affinity for CYP2A13.1 than for CYP2A13.2. Additional experiments with the Arg25Gln and Arg257Cys variant proteins suggested that this differential antibody binding was caused by the Arg257Cys variation. Using Bcepred, a B-cell epitope prediction program (Saha and Raghava, 2004), we found that the epitopes for CYP2A13.2, predicted based on accessibility and surface exposure, did not include Cys257, whereas the epitopes for CYP2A13.1 did include Arg257. Thus, Arg257 appears to be a part of the epitope recognized by the A106 antibody. Unfortunately, we anticipate that it will be difficult to generate a CYP2A13.2-specific antibody based on the unique presence of the Cys257. 
The CYP2A13*1 and CYP2A13*2 alleles also differ from one another in their expression levels in human lung tissue, with CYP2A13*2 mRNA detected at $\sim 30 \%$ lower levels than the CYP2A13*1 mRNA, in an allelic expression analysis. However, it remains to be determined whether the levels of CYP2A13.2 protein are also decreased and, if they are, whether the extent of decrease in CYP2A13.2 protein is similar to the extent of decrease in CYP2A13*2 mRNA. Indirect evidence, including the stability of heterologously expressed CYP2A13.2 and the general correlation between CYP2A13 mRNA and CYP2A13 protein levels in the human lung (Zhang et al., 2007), suggests that CYP2A13.2 protein is expressed, even though direct evidence for the occurrence of the CYP2A13.2 protein has yet to be obtained.

Assuming that the differences in allelic mRNA expression observed in this study are mirrored at the protein level, a heterozygous, CYP2A13*1/*2 individual would be expected to show $\sim 30 \%$ less activity in NNK a-hydroxylation than would a CYP2A13*1/*1 individual, while a homozygous, CYP2A13*2/*2 individual would be expected to show $\sim 60 \%$ less activity ( 30 $40 \%$ less total CYP2A13 protein, which is already $\sim 30-40 \%$ less active in NNK $\alpha$ -

hydroxylation than is CYP2A13.1). Although these differences appear small, they could have sufficed to contribute measurably to the decrease in the risk of lung adenocarcinoma observed for patients with the Arg257Cys variation (Wang et al., 2003), particularly given the reported occurrence of a threshold dose level in NNK-induced tumor incidence or multiplicity, in both mouse and rat (Peterson and Hecht 1991; Hecht 1998).

In $\mathrm{A} / \mathrm{J}$ mouse lung, it was observed that tumor multiplicity, as well as the levels of $\mathrm{O}^{6}$ methylguanine adduct, increased sharply when the dose of NNK exceeded 2-3 $\mu \mathrm{mol} /$ mouse (for a single i.p. injection) (Peterson and Hecht 1991). In F-344 rats, treated with NNK either as a subcutaneous injection or else administered in drinking water, a sharp increase in tumor incidence, as well as in levels of $\mathrm{O}^{6}$-methylguanine adduct in Clara cells, was observed when the total NNK dose reached $\sim 0.1-0.3 \mathrm{mmol} / \mathrm{kg}$ (reviewed in Hecht 1998). Assuming that a threshold dose also exist for human lung tumor formation, a relatively small (e.g., 30\%) decrease in the rate of metabolic activation of NNK could dampen the rate of formation of DNA adducts sufficiently that effective repair of the adducted DNA becomes possible. Thus, individuals with the Arg257Cys variation would in effect have a higher threshold dose for NNK tumorigenesis than would CYP 2 A $13 * 1 / * 1$ individuals. Nonetheless, it remains possible that other, yet to be identified, genetic variations in linkage disequilibrium with the CYP2A13*2 allele can have also contributed to the observed decrease in the risk of smokinginduced lung adenocarcinoma.

A 26-bp deletion has been identified, for the first time, in the 5'-flanking region of the CYP2A13*2 allele. Subsequent experiments indicated that deletion of this 26-bp sequence from a 2 -kb CYP2A $13 * 1$ promoter construct leads to a decrease $(\sim 30 \%)$ in promoter activity; such a result strongly suggests that the 26-bp deletion is at least partly the cause of the low allelic expression of the CYP2A13*2 allele in human lung. An analysis of this 26-bp region using the TFSEARCH program (Heinemeyer et al., 1998) identified potential binding sites for a number of transcriptions factors, including AP-1, Gata-1, C/EBP $\alpha$ and C/EBP $\beta$, with identity scores ranging from 71.1 for $\mathrm{C} / \mathrm{EBP} \alpha$ to 76.5 for Ap-1. In this context, recent findings from our laboratory have identified the C/EBPs as transcription factors involved in CYP2A13 gene regulation (Ling et al., 2007).

In summary, the results of the present study indicated that the CYP2A13*2 allele is expressed at lower levels than is the CYP2A13*1 allele in CYP2A13*1/CYP2A13*2 heterozygotes, and that the CYP2A13.2 protein has lower activity than does CYP2A13.1 toward NNK and several other substrates tested. The differences, either in expression levels or in enzyme activities, between the two CYP2A13 alleles or proteins were relatively small; however, in combination, 
these differences could account, at least in part, for the reported association of the CYP2A13*2 allele with decreased incidence of lung adenocarcinoma in smokers.

\section{Acknowledgements}

We gratefully acknowledge the use of the services of the Molecular Genetics Core Facility of the Wadsworth Center. We thank the Cooperative Human Tissue Network and Dr. Alan Fantel of the Birth Defect Research Laboratory at the University of Washington (funded by NIH grant HD00836) for providing human tissues, and Dr. Adriana Verschoor for reading the manuscript.

This work was supported in part by Public Health Service grant CA092596 from the National Institutes of Health.

\section{ABBREVIATIONS}

P450

cytochrome P450

CPR

cytochrome $\mathrm{P} 450$ reductase

HMPA

hexamethylphosphoramide

2'-MAP

2'-methoxyacetophenone

DMA

$N, N$-dimethylaniline

NMPhA

$N$-nitrosomethylphenylamine

HPLC

high performance liquid chromatography

NNAL

4-(methylnitrosamino)-1-(3-pyridyl)-1-butanol

NNK

4-(methylnitrosamino)-1-(3-pyridyl)-1-butanone

PCR

polymerase chain reaction

SNPs

single-nucleotide polymorphisms

UTR

untranslated region

TBST

Tris-buffered saline (100 mM Tris-Cl, pH 7.5, $150 \mathrm{mM} \mathrm{NaCl}$, and $2.7 \mathrm{mM} \mathrm{KCl}$ ) containing $0.1 \%$ Tween-20

WT

wild-type

bp

base pair

Drug Metab Dispos. Author manuscript; available in PMC 2009 November 1. 


\section{References}

Bao Z, He XY, Ding X, Prabhu S, Hong JY. Metabolism of nicotine and cotinine by human cytochrome P450 2A13. Drug Metab Dispos 2005;33:258-261. [PubMed: 15528319]

Draper AJ, Madan A, Parkinson A. Inhibition of coumarin 7-hydroxylase activity in human liver microsomes. Arch Biochem Biophy 1997;341:47-61.

Fujieda M, Yamazaki H, Kiyotani K, Muroi A, Kunitoh H, Dosaka-Akita H, Sawamura Y, Kamataki T. Eighteen novel polymorphisms of the CYP2A13 gene in Japanese. Drug Metab Pharmacokinet 2003;18:86-90. [PubMed: 15618722]

Fernandez-Salguero P, Hoffman SM, Cholerton S, Mohrenweiser H, Raunio H, Rautio A, Pelkonen O, Huang JD, Evans WE, Idle JR. A genetic polymorphism in coumarin 7-hydroxylation: sequence of the human CYP2A genes andidentification of variant CYP2A6 alleles. Am J Hum Genet 1995;57:651660. [PubMed: 7668294]

Gotoh O. Substrate recognition sites in cytochrome P450 family 2 (CYP2) proteins inferred from comparative analyses of amino acid and coding nucleotide sequences. J Biol Chem 1992;267:83-90. [PubMed: 1730627]

Gu J, Zhang QY, Genter MB, Lipinskas TW, Negishi M, Nebert DW, Ding X. Purification and characterization of heterologously expressed mouse CYP2A5 and CYP2G1: role in metabolic activation of acetaminophen and 2,6-dichlorobenzonitrile in mouse olfactory mucosal microsomes. J Pharmacol Exp Ther 1998;285:1287-1295. [PubMed: 9618435]

Hasemann CA, Kurumbail RG, Boddupalli SS, Peterson JA, Deisenhofer J. Structure and function of cytochromes P450: a comparative analysis of three crystal structures. Structure 1995;3:41-62. [PubMed: 7743131]

He XY, Shen J, Ding X, Lu AY, Hong JY. Identification of Val117 and Arg372 as critical amino acid residues for the activity difference between human CYP2A6 and CYP2A13 in coumarin 7hydroxylation. Drug Metab Dispos 2004;32:1516-1521. [PubMed: 15333516]

He XY, Tang L, Wang SL, Cai QS, Wang JS, Hong JY. Efficient activation of aflatoxin B1 by cytochrome $\mathrm{P} 450$ 2A13, an enzyme predominantly expressed in human respiratory tract. Int J Cancer 2006;118:2665-2671. [PubMed: 16385575]

Hecht SS. Biochemistry, biology and carcinogenicity of tobacco-specific $N$-nitrosamines. Chem Res Toxicol 1998;11:559-603. [PubMed: 9625726]

Heinemeyer T, Wingender G, Reuter I, Hermjakob H, Kel A, Kel O, Ignatieva E, Ananko E, Podkolodnaya O, Kolpakov F, Podkolodny N, Kolchanov N. Databases on Transcriptional Regulation: TRANSFAC, TRRD, and COMPEL. Nucleic Acids Res 1998;26:364-370.

Human Cytochrome P450 Allele Nomenclature Committee. [online] URL: http://www.cypalleles.ki.se/

Jalas JR, Ding X, Murphy SE. Comparative metabolism of the tobacco-specific nitrosamines 4(methylnitrosamino)-1-(3-pyridyl)-1-butanone and 4-(methylnitrosamino)-1-(3-pyridyl)-1-butanol by rat cytochrome P450 2A3 and human cytochrome P450 2A13. Drug Metab Dispos 2003;31:1199_ 1202. [PubMed: 12975327]

Jalas JR, Hecht SS, Murphy SE. Cytochrome P450 enzymes as catalysts of metabolism of 4(methylnitrosamino)-1-(3-pyridyl)-1-butanone, a tobacco specific carcinogen. Chem Res Toxicol 2005;18:95-110. [PubMed: 15720112]

Jiang JH, Jia WH, Chen HK, Feng BJ, Qin HD, Pan ZG, Shen GP, Huang LX, Feng QS, Chen LZ, Lin DX, Zeng YX. Genetic polymorphisms of CYP2A13 and its relationship to nasalpharyngeal carcinoma in the Cantonese population. J Transl Med 2004;2:24. [PubMed: 15222883]

Ling G, Wei Y, Ding X. Transcriptional regulation of human CYP2A13 expression in the respiratory tract by CCAAT/enhancer binding protein and epigenetic modulation. Mol Pharmacol 2007;71:807816. [PubMed: 17148654]

Liu C, Zhou X, Gonzalez FJ, Ding X. Baculovirus-mediated expression and characterization of rat CYP2A3 and human CYP2A6: role in metabolic activation of nasal toxicants. Mol Pharmacol 1996;50:781-788. [PubMed: 8863822] 
Mäenpää J, Sigusch H, Raunio H, Syngelmä T, Vuorela P, Vuorela H, Pelkonen O. Differential inhibition of coumarin 7-hydroxylase activity in mouse and human liver microsomes. Biochem Pharmacol 1993;45:1035-1042. [PubMed: 8461033]

Nakajima M, Itoh M, Sakai H, Fukami T, Katoh M, Yamazaki H, Kadlubar FF, Imaoka S, Funae Y, Yokoi T. CYP2A13 expressed in human bladder metabolically activates 4-aminobiphenyl. Int J Cancer 2006;119:2520-2526. [PubMed: 16988941]

Nash T. The colorimetric estimation of formaldehyde by means of the Hantzsch reaction. Biochem $\mathbf{J}$ 1953;55:416-421. [PubMed: 13105648]

Omura T, Sato R. The carbon monoxide-binding protein of liver microsomes. I. Evidence for its hemoprotein nature. J Biol Chem 1964;239:2370-2378. [PubMed: 14209971]

Peterson LA, Hect SS. O6-methylguanine is a critical determinant of 4-(methylnitrosamino)-1-(3pyridyl)-1-butanone tumorigenesis in A/J mouse lung. Cancer Res 1991;51:5557-5564. [PubMed: 1913675]

Rosner, B. Fundamentals of Biostatistics. 6. Brooks/Cole; CA: 2006.

Saha, S.; Raghava, GPS. BcePred:Prediction of Continuous B-Cell Epitopes in Antigenic Sequences Using Physico-chemical Properties. In: Nicosia, G.; Cutello, V.; Bentley, PJ.; Timis, J., editors. ICARIS 2004, LNCS 3239. Springer; Berlin: 2004. p. 197-204.

Schlicht KE, Michno N, Smith BD, Scott EE, Murphy SE. Functional characterization of CYP2A13 polymorphisms. Xenobiotica 2007;37:1439-1449. [PubMed: 17922361]

Scott EE, White MA, He YA, Johnson EF, Stout CD, Halpert JR. Structure of mammalian cytochrome P450 2B4 complexed with 4-(4-chlorophenyl)imidazole at 1.9-A resolution: insight into the range of P450 conformations and the coordination of redox partner binding. J Biol Chem 2004;279:2729427301. [PubMed: 15100217]2004

Smith BD, Sanders JL, Porubsky PR, Lushington GH, Stout CD, Scott EE. Structure of the human lung cytochrome P450 2A13. J Biol Chem 2007;282:17306-17313. [PubMed: 17428784]

Su T, Bao ZP, Zhang QY, Smith TJ, Hong JY, Ding X. Human cytochrome P450 CYP2A13: predominant expression in the respiratory tract and its high efficiency metabolic activation of a tobacco-specific carcinogen, 4-(methylnitrosamino)-1-(3-pyridyl)-1-butanone. Cancer Res 2000;60:5074-5079. [PubMed: 11016631]

von Weymarn LB, Zhang QY, Ding X, Hollenberg PF. Effects of 8-methoxypsoralen on cytochrome P450 2A13. Carcinogenesis 2005;3:621-629. [PubMed: 15579482]

Wang H, Tan W, Hao B, Miao X, Zhou G, He F, Lin D. Substantial reduction in risk of lung adenocarcinoma associated with genetic polymorphism in CYP2A13, the most active cytochrome P450 for the metabolic activation of tobacco-specific carcinogen NNK. Cancer Res 2003;63:80578061. [PubMed: 14633739]

Wang SL, He XY, Shen J, Wang JS, Hong JY. The missense genetic polymorphisms of human CYP2A13: functional significance in carcinogen activation and identification of a null allelic variant. Toxcicol Sci 2006;94:38-45.

Wester MR, Johnson EF, Marques-Soares C, Dansette PM, Mansuy D, Stout CD. Structure of a substrate complex of mammalian cytochrome P450 2C5 at 2.3 A resolution: evidence for multiple substrate binding modes. Biochemistry 2003;42:6370-6379. [PubMed: 12767218]

Wester MR, Yano JK, Schoch GA, Yang C, Griffin KJ, Stout CD, Johnson EF. The structure of human cytochrome P450 2C9 complexed with flurbiprofen at 2.0-A resolution. J Biol Chem 2004;279:35630-35637. [PubMed: 15181000]

Wong HL, Zhang X, Zhang QY, Gu J, Ding X, Hecht SS, Murphy SE. metabolic activation of the tobacco carcinogen 4-(methylnitrosamino)-(3-pyridyl)-1-butanone by cytochrome P450 2A13 in human fetal nasal microsomes. Chem Res Toxicol 2005;18:913-918. [PubMed: 15962925]

Zhang Q-Y, Raner G, Ding X, Dunbar D, Coon MJ, Kaminsky LS. Characterization of the cytochrome P450 CYP2J4: expression in rat small intestine and role in retinoic acid biotransformation from retinal. Arch Biochem Biophys 1998;353:257-264. [PubMed: 9606960]

Zhang X, Caggana M, Cutler TL, Ding X. Development of a real-time polymerase chain reaction-based method for the measurement of relative allelic expression and identification of $C Y P 2 A 13$ alleles with decreased expression in human lung (2004). J Pharmacol Exp Ther 2004;311:373-381. [PubMed: $15175424]$ 
Zhang X, Chen Y, Liu Y, Ren X, Zhang QY, Caggana M, Ding X. Single nucleotide polymorphisms of the human CYP2A13 gene: evidence for a null allele. Drug Metab Dispos 2003;31:1081-1085. [PubMed: 12920161]

Zhang X, D'Agostino J, Wu H, Zhang QY, von Weymarn L, Murphy SE, Ding X. CYP2A13: variable expression and role in human lung microsomal metabolic activation of the tobacco-specific carcinogen 4-(methylnitrosamino)-1-(3-pyridyl)-1-butanone. J Pharmacol Exp Ther 2007;323:570578. [PubMed: 17671098]

Zhang X, Su T, Zhang QY, Gu J, Caggana M, Li H, Ding X. Genetic polymorphisms of the human CYP2A13 gene: identification of single-nucleotide polymorphisms and functional characterization of an Arg257Cys variant. J Pharmacol Exp Ther 2002;302:416-423. [PubMed: 12130698]

Zhu LR, Thomas PE, Lu G, Reuhl KR, Yang GY, Wang LD, Wang SL, Yang CS, He XY, Hong JY. CYP2A13 in human respiratory tissues and lung cancers: an immunohistochemical study with a new peptide-specific antibody. Drug Metab Dispos 2006;34:1672-1676. [PubMed: 16815959] 


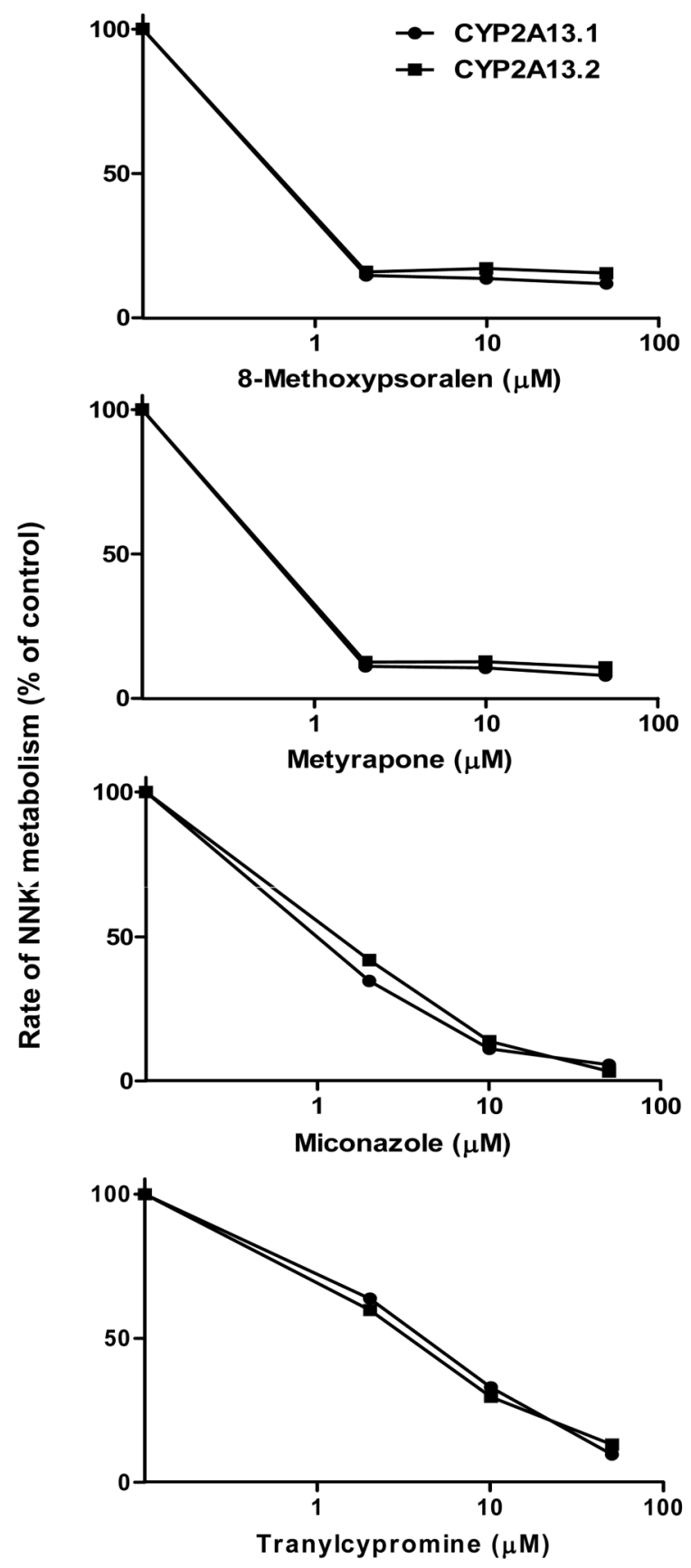

Fig. 1.

Inhibition of CYP2A13.1- and CYP2A13.2-mediated NNK $\alpha$-hydroxylation by 8methoxypsoralen, metyrapone, miconazole, and tranylcypromine. Incubation mixtures consisted of $10 \mu \mathrm{M}$ NNK (containing $1 \mu \mathrm{Ci}\left[5-{ }^{3} \mathrm{H}\right] \mathrm{NNK}$ ), 0-50 $\mu \mathrm{M}$ inhibitor, $5 \mathrm{mM}$ sodium bisulfite, $30 \mathrm{pmol}$ rat CPR, $10 \mathrm{pmol}$ of CYP2A13, and other components as described in the legend to Table 2, in a total volume of $0.4 \mathrm{ml}$. Reactions were carried out at $37^{\circ} \mathrm{C}$ for $5 \mathrm{~min}$. The reactions were performed in duplicate, and the values (relative rates of keto aldehyde formation) shown are typical of two separate experiments performed. 


\section{A13.1 2A13.2 2A6}
A
Polyclonal anti-CYP2A5

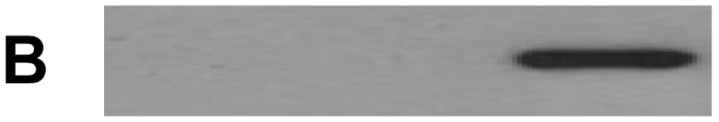
\#151-45-4 anti-CYP2A6
C

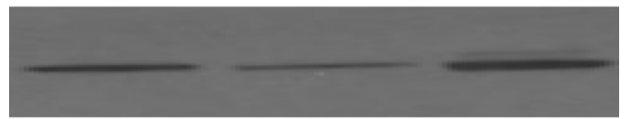
\#A106 anti-CYP2A6
R257C R25Q (2A13)
D

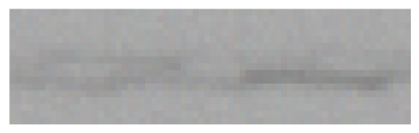
\#A106 anti-CYP2A6
$\mathbf{E}$

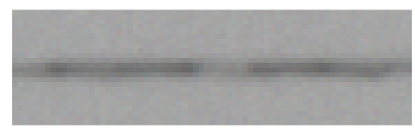
Polyclonal anti-CYP2A5

Fig. 2.

Immunoblot detection of CYP2A6, CYP2A13.1, and CYP2A13.2 proteins with various antiCYP2A antibodies. A.-C. Heterologously expressed CYP2A13.1, CYP2A13.2, and CYP2A6 (0.5 pmol each) were analyzed on immunoblots with rabbit antiserum to CYP2A5 (panel A), \#151-45-4 anti-CYP2A6 (panel B), or \#A106 anti-CYP2A6 (panel C). D, E. Heterologously expressed CYP2A13 variants, Arg25Gln (R25Q) and Arg257Cys (R257C) (0.1 pmol), were analyzed on immunoblots with \#A106 anti-CYP2A6 (panel D) or rabbit Anti-CYP2A5 (panel E). Results shown are typical of 2-3 experiments performed. 
A

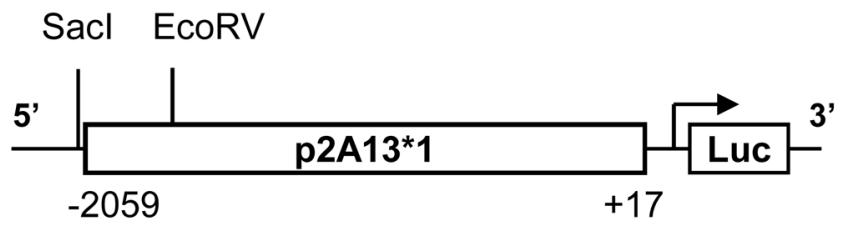

Sacl EcoRV

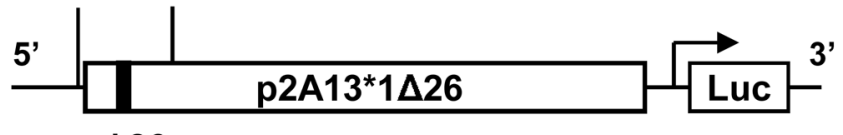

$\Delta 26$

$(-1913$ to -1888$)$

B

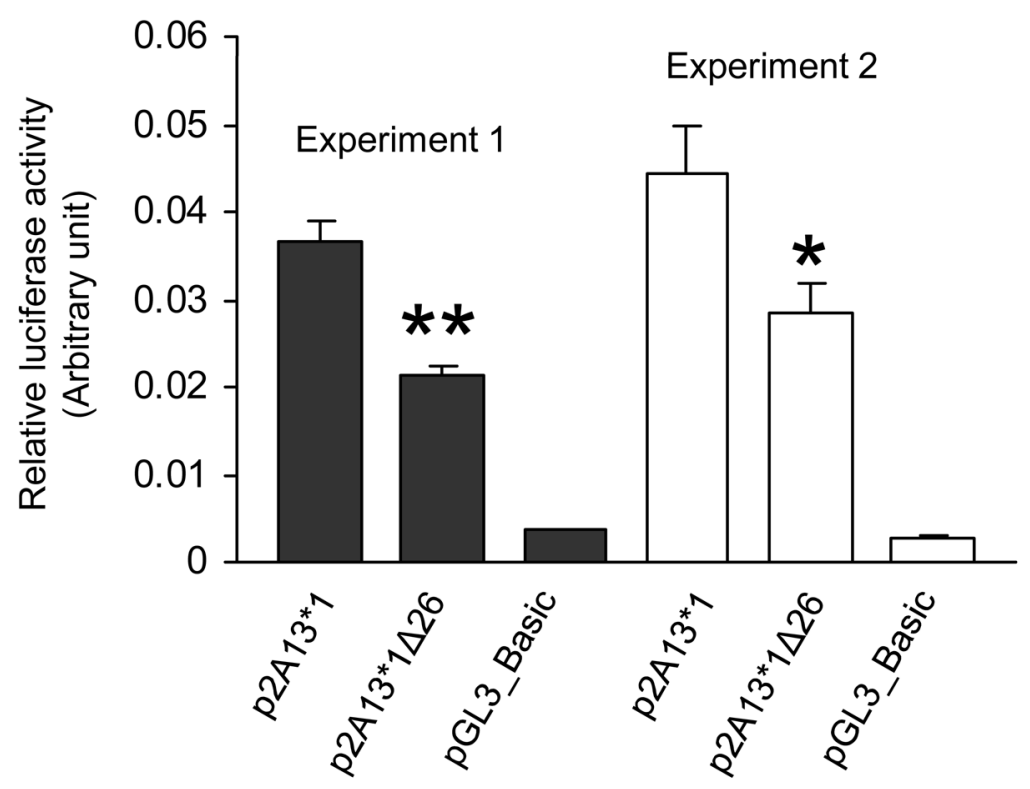

Fig. 3.

Functional analysis of CYP2A13 promoter. A. Structure of the reporter constructs, p2A13*1 and $\mathrm{p} 2 \mathrm{~A} 13 * 1 \Delta 26$. B. A549 cells were harvested $48 \mathrm{~h}$ after transfection with a firefly luciferase reporter gene construct and the internal control Renilla luciferase construct (pRL-SV40), for determination of luciferase activities. pGL3_Basic was included as a negative control. Data from two separate experiments are shown; for each experiment, each construct was analyzed in triplicate 6-well plates, and the activities of firefly luciferase in cell lysates were normalized to those of co-transfected Renilla luciferase. The results shown are means \pm S.D. $* p<0.05$; $* * p<0.001$ (Student's t-test). 
TABLE 1

Catalytic activities of the CYP2A13.1 and CYP2A13.2 toward four xenobiotic compounds

Reaction mixtures contained $50 \mathrm{mM}$ phosphate buffer, pH 7.4, 1 mM NADPH, $1 \mathrm{mM}$ substrate, a reconstituted P450 system consisting of $0.1 \mu \mathrm{M}$ recombinant P450 in Sf9 microsomes and $0.3 \mu \mathrm{M}$ purified rat CPR. The reactions were carried out at $37^{\circ} \mathrm{C}$ for $10 \mathrm{~min}$, during which product formation was linear with time. Values presented are means \pm S.D. from three duplicate determinations.

\begin{tabular}{|c|c|c|c|}
\hline \multirow[t]{2}{*}{ Substrate } & \multicolumn{2}{|c|}{ Rate (nmol/min/nmol P450) } & \multirow{2}{*}{$\begin{array}{c}\text { Extent of activity difference }(\%) \\
{[(2 \mathrm{~A} 13.1-2 \mathrm{~A} 13.2) / 2 \mathrm{~A} 13.1] \times 100 \%}\end{array}$} \\
\hline & CYP2A13.1 & CYP2A13.2 & \\
\hline $\begin{array}{l}\text { NMPhA } \\
\text { DMA } \\
2^{\prime}-\mathrm{MAP} \\
\text { HMPA }\end{array}$ & $\begin{array}{c}16.1 \pm 0.6 \\
8.9 \pm 0.4 \\
10.6 \pm 0.5 \\
6.2 \pm 0.4\end{array}$ & $\begin{array}{l}13.0 \pm 0.3^{a} \\
6.7 \pm 0.2^{b} \\
8.1 \pm 0.5^{a} \\
4.1 \pm 0.3^{a}\end{array}$ & $\begin{array}{l}19 \\
25 \\
24 \\
34\end{array}$ \\
\hline
\end{tabular}


TABLE 2

Metabolism of NNK by heterologously expressed CYP2A13.1 and CYP2A13.2

Incubation mixtures contained $100 \mathrm{mM}$ sodium phosphate buffer, pH 7.4, $1.0 \mathrm{mM}$ EDTA, $3.0 \mathrm{mM} \mathrm{MgCl} 2$, an NADPHgenerating system $(5.0 \mathrm{mM}$ glucose-6-phosphate, $1.0 \mathrm{mM} \mathrm{NADPH}$, and 1.5 Units of glucose-6-phosphate dehydrogenase), 2-50 $\mu \mathrm{M}$ NNK (containing $\left.1 \mu \mathrm{Ci}\left[5-{ }^{3} \mathrm{H}\right] \mathrm{NNK}\right), 5.0 \mathrm{mM}$ sodium bisulfite, 20 or 40 pmol of purified rat CPR, and 5 or $10 \mathrm{pmol}$ of CYP2A13, in a total volume of $0.4 \mathrm{ml}$. Reactions were carried out at $37^{\circ} \mathrm{C}$ for $5-10 \mathrm{~min}$. NNK metabolites were determined using radiometric HPLC, as described in Materials and Methods. The $K_{\mathrm{m}}$ and $\mathrm{V}_{\text {max }}$ values represent means \pm S.D. from three separate determinations.

\begin{tabular}{|c|c|c|c|c|}
\hline \multirow[t]{2}{*}{ Enzyme } & \multicolumn{2}{|c|}{ Keto Aldehyde } & \multicolumn{2}{|c|}{ Keto Alcohol } \\
\hline & $\underset{\mathrm{nmol} / \mathrm{min} / \mathrm{nmol}}{\mathrm{V}_{\max }}$ & $\begin{array}{l}K_{\mathbf{m}} \\
\mu \mathrm{M}\end{array}$ & $\underset{\mathrm{nmol} / \mathrm{min} / \mathrm{nmol} \mathbf{P 4 5 0}}{\mathrm{V}_{\max }}$ & $\begin{array}{l}K_{\mathbf{m}} \\
\mu \mathrm{M}\end{array}$ \\
\hline $\begin{array}{l}\text { CYP2A } 13.1 \\
\text { CYP2A } 13.2\end{array}$ & $\begin{array}{c}5.1 \pm 0.2 \\
3.6 \pm 0.1 b\end{array}$ & $\begin{array}{l}6.8 \pm 1.1 \\
6.4 \pm 1.0\end{array}$ & $\begin{array}{l}2.0 \pm 0.2 \\
1.1 \pm 0.2^{a}\end{array}$ & $\begin{array}{l}5.7 \pm 1.6 \\
4.7 \pm 2.2\end{array}$ \\
\hline
\end{tabular}


TABLE 3

Metabolism of NNK by heterologously expressed CYP2A13.1 and CYP2A13.2 with varying amounts of CPR Contents of incubation mixtures were the same as described in the legend of Table 2, except that $10 \mu \mathrm{MNNK}$ (containing $\left.1 \mu \mathrm{Ci}\left[5-{ }^{3} \mathrm{H}\right] \mathrm{NNK}\right), 5,10$, or $30 \mathrm{pmol}$ of rat CPR, and 5 or $10 \mathrm{pmol}$ of CYP2A13, were used. Reactions were carried out at $37^{\circ} \mathrm{C}$ for $10 \mathrm{~min}$. Data represent the average of two determinations; individual values varied by $<15 \%$ of the mean.

\begin{tabular}{llll}
\hline Enzymes & Rate of keto aldehyde formation (nmol/min/nmol P450) & \\
\cline { 2 - 4 } & CYP/CPR molar ratio & $\mathbf{1 : 3}$ & $\mathbf{1 : 1}$ \\
\hline 10 pmol CYP2A13.1 (a) & & 2.2 & 1.2 \\
10 pmol CYP2A13.2 (b) & & 1.5 & 0.9 \\
5 pmol CYP2A13.1 & & 0.7 & 1.0 \\
+ 5 pmol CYP2A13.2 & & 0.5 & 1.9 \\
Calculated value [(a+b)/2] & & 0.6 \\
\hline
\end{tabular}

